\title{
CYP11A1 expression in bone is associated with aromatase inhibitor-related bone loss
}

\author{
M Rodríguez-Sanz ${ }^{1}$, N García-Giralt ${ }^{1}$, D Prieto-Alhambra ${ }^{1,3,4,5}$, S Servitja ${ }^{6}$, S Balcells ${ }^{7}$, \\ R Pecorelli ${ }^{1,2}$, A Díez-Pérez ${ }^{1,2}$, D Grinberg ${ }^{7}$, I Tusquets ${ }^{6}$ and $X$ Nogués $^{1,2}$ \\ ${ }^{1}$ IMIM (Hospital del Mar Research Institute), Red Temática de Investigación Cooperativa en Envejecimiento y \\ Fragilidad (RETICEF), ISCIII, Carrer del Doctor Aiguader 88, 08003 Barcelona, Spain \\ ${ }^{2}$ Internal Medicine Department, Hospital del Mar, Universitat Autònoma de Barcelona, Barcelona, Spain \\ ${ }^{3}$ IDIAP Jordi Gol Primary Care Research Institute, Universitat Autònoma de Barcelona, Barcelona, Spain \\ ${ }^{4}$ Nuffield Department of Orthopaedics, Rheumatology and Musculoskeletal Sciences, Oxford NIHR Musculoskeletal \\ Biomedical Research Unit, University of Oxford, Oxford, UK \\ ${ }^{5}$ MRC Lifecourse Epidemiology Unit, University of Southampton, Southampton, UK \\ ${ }^{6}$ Medical Oncology Department, IMIM (Hospital del Mar Research Institute), Hospital del Mar, Universitat \\ Autònoma de Barcelona, Barcelona, Spain \\ ${ }^{7}$ Departament de Genètica, Universitat de Barcelona, IBUB, Centro de Investigación Biomédica en Red de \\ Enfermedades Raras (CIBERER), ISCIII, Barcelona, Spain
}

\author{
Correspondence \\ should be addressed \\ to N García-Giralt \\ Email \\ ngarcia@imim.es
}

\begin{abstract}
Aromatase inhibitors (Als) used as adjuvant therapy in postmenopausal women with hormone receptor-positive breast cancer cause diverse musculoskeletal side effects that include bone loss and its associated fracture. About half of the 391 patients treated with Als in the Barcelona-Aromatase induced bone loss in early breast cancer cohort suffered a significant bone loss at lumbar spine (LS) and/or femoral neck (FN) after 2 years on Al-treatment. In contrast, up to one-third (19.6\% LS, 38.6\% FN) showed no decline or even increased bone density. The present study aimed to determine the genetic basis for this variability. SNPs in candidate genes involved in vitamin $D$ and estrogen hormone-response pathways (CYP11A1, CYP17A1, HSD3B2, HSD17B3, CYP19A1, CYP2C19, CYP2C9, ESR1, $D H C R 7, G C, C Y P 2 R 1, C Y P 27 B 1, V D R$ and CYP24A1) were genotyped for association analysis with Al-related bone loss (AIBL). After multiple testing correction, 3 tag-SNPs (rs4077581, s11632698 and rs900798) located in the CYP11A1 gene were significantly associated $(P<0.005)$ with FN AIBL at 2 years of treatment. Next, CYP11A1 expression in human fresh bone tissue and primary osteoblasts was demonstrated by RT-PCR. Both common isoforms of human cholesterol side-chain cleavage enzyme (encoded by CYP11A1 gene) were detected in osteoblasts by western blot. In conclusion, the genetic association of CYP11A1 gene with AIBL and its expression in bone tissue reveals a potential local function of this enzyme in bone metabolism regulation, offering a new vision of the steroidogenic ability of this tissue and new understanding of Al-induced bone loss.
\end{abstract}

\author{
Key Words \\ - CYP11A1 \\ - aromatase inhibitors \\ bone loss \\ breast cancer \\ - genetic association
}

http://jme.endocrinology-journals.org DOI: 10.1530/JME-15-0079
() 2015 Society for Endocrinology Printed in Great Britain
Published by Bioscientifica Ltd
Journal of Molecular Endocrinology (2015) 55, 69-79 


\section{Introduction}

Aromatase inhibitors (AIs) are commonly used as adjuvant therapy in postmenopausal women with hormone receptor-positive breast cancer. Although AIs are generally well tolerated with few serious adverse events, a number of musculoskeletal side effects affecting quality of life have been noted and often lead to discontinuation of therapy (Eastell et al. 2006, Henry et al. 2008).

The most common side effects reported with AIs are exacerbation of menopausal symptoms as a result of low estrogen levels; these include pain syndromes, bone loss and associated fracture (Eastell et al. 2008, Laroche et al. 2014). Several prospective studies and clinical trials have noted the need for assessment and treatment of these musculoskeletal adverse events (Reid et al. 2008, Brufsky et al. 2009, Servitja et al. 2012). In particular, bone mineral density (BMD) reduction and fracture incidence associated with AI therapy can be significantly reduced by oral bisphosphonates (BP) treatment (Bouvard et al. 2014).

We are currently conducting a prospective, nonselected, observational, clinical cohort study (BarcelonaAromatase induced bone loss in early breast cancer (B-ABLE)) to investigate the musculoskeletal side effects of AI in postmenopausal women with early breast cancer. Previously, we reported a genetic association with AI-related arthralgia and therapy discontinuation in this cohort. SNPs in CYP17A1, CYP27B1 and VDR genes (involved in the estrogen and vitamin D signaling pathways) could predict the risk of pain syndromes (Garcia-Giralt et al. 2013).

About half of the B-ABLE cohort patients had more than $3 \%$ bone loss after 2 years on AI treatment at lumbar spine (LS) and/or at femoral neck (FN). In contrast, up to a third of patients did not lose, or even gained, bone density. Clearly, susceptibility to side effects from AI-treatment varies between individuals and this variability may be explained, in part, by individual genetic background.

It is well known that estrogen and vitamin D endocrine systems play an important role in bone metabolism (Felson et al. 1993, Cranney et al. 2007). Depletion of any of these hormones leads to a bone mass reduction, which in some cases is very severe (Eriksen \& Glerup 2002). In postmenopausal women, the only sources of estrogens are through the aromatase function in peripheral tissues and through steroid sulfatase activity (Reed et al. 2005), which is also active in bone (Muir et al. 2004). Therefore, the aromatase inhibition, especially at the bone tissue level, would cause a major BMD loss (Bouvard et al. 2014). However, remnant estrogen levels after aromatase inhibition may modulate the degree of bone loss. Hence, the estrogen synthesis pathway can play an important role in the final amount of available estrogen. In addition, serum 25-hydroxy-vitamin D (25(OH)D) status affects the rate of bone loss in patients with AI therapy and vitamin D supplementation to target threshold of $\geq 40 \mathrm{ng} / \mathrm{ml}$ protects against AI-related bone loss (AIBL) (Prieto-Alhambra et al. 2011). Therefore, both the vitamin D metabolism and the response to vitamin $\mathrm{D}$ treatment may be essential to the regulation of bone metabolism.

We hypothesized that genetic variants in genes involved in the estrogen and vitamin D synthesis and response can explain part of the variability in bone loss observed in AI-treated patients. Hence, we genotyped tagSNPs in the genes of the estrogen and vitamin D signaling pathway to analyze their association with bone loss at 1 and 2 years after starting AI treatment.

\section{Materials and methods}

\section{Ethics statement}

The study protocols were approved by the corresponding ethics committee (Hospital del Mar Human Research Ethics Committee). The approved protocols for obtaining DNA from blood samples and fresh bone (and primary osteoblasts) from hip samples otherwise discarded at the time of orthopedic surgery were explained to potential study participants, who provided written informed consent before being included in the study.

\section{Study population}

Details on study design, recruitment methods and study population have been described elsewhere (Nogues et al. 2010) and are briefly summarized below. B-ABLE is a prospective, observational, clinical cohort study. Postmenopausal women diagnosed with hormone receptorpositive breast cancer and candidates for AI treatment attending the outpatient Breast Cancer Unit at Hospital del Mar (Barcelona, Spain) were consecutively invited to participate in the study. Eligible participants with history of any bone disease, rheumatoid arthritis, metabolic or endocrine diseases, prior diagnosis of Paget's bone disease or osteomalacia, oral corticosteroids, or any other boneactive drug except tamoxifen were excluded.

Interventions Participants were treated with AIs (letrozole, exemestane or anastrozole) according to the American Society of Clinical Oncology (ASCO)

Published by Bioscientifica Ltd 
recommendations (Winer et al. 2005), starting within 6 weeks after surgery or 1 month after the last cycle of chemotherapy, or alternatively, after 2 to 3 years of tamoxifen therapy.

All patients received supplemental calcium and vitamin D tablets (1000 $\mathrm{mg}$ and $800 \mathrm{IU}$ daily), and those with baseline vitamin D deficiency $(<30 \mathrm{ng} / \mathrm{ml})$ received an additional dose of $16000 \mathrm{IU}$ of oral cholecalciferol every 2 weeks.

Measurements Bone mineral density At baseline and annually thereafter until end of treatment, BMD was measured at the LS (L1-L4), FN and total hip using a dualenergy X-ray densitometer QDR 4500 SL (Hologic, Waltham, MA, USA), following the usual protocol in our unit. In our department, the in vivo $\mathrm{CV}$ of this technique ranges from $1.0 \%$ at $\mathrm{LS}$ to $1.65 \%$ at $\mathrm{FN}$. Images were subjected to rigorous scrutiny, especially when interpreting follow-up scans; those presenting scan artifacts causing falsely elevated BMD (degenerative disc disease with osteophytes, osteoarthritis with hyperostosis of the facet joints, vertebral fractures and/or aortic calcification) according to the description by Blake et al. (2013) were excluded from analysis.

Other assessments Information on a large number of clinical variables was recorded at the time of enrollment, including age at recruitment, age at menarche and menopause, lactation, parity, previous chemotherapy and radiotherapy, adjuvant treatments, weight, height, plasma levels of $25(\mathrm{OH}) \mathrm{D}$, calcium intake and smoking status.

\section{Selection of candidate genes}

Genes encoding key factors in the synthesis and response of the estrogens and vitamin $\mathrm{D}$ hormones were selected for the genetic association study (Fig. 1). Eight candidate genes were selected to test the estrogen hypothesis: CYP11A1, CYP17A1, HSD3B2, HSD17B3, CYP19A1, CYP2C19, CYP2C9 and ESR1. Six genes were selected for the vitamin D hypothesis: GC, CYP27B1, VDR and CYP24A1.

\section{Selection of SNPs}

SNPs were selected on the basis of the following criteria: i) minor allele frequency (MAF) $>0.05$; ii) haplotype tagging (tag-SNPs) according to HapMap project in CEU population; iii) putative functional polymorphisms; and iv) previous association with other musculoskeletal phenotypes: plasma 25(OH)D concentrations (Wang et al. 2010), BMD (Kobayashi et al. 1996, Langdahl et al. 2000,
Zarrabeitia et al. 2004, Enjuanes et al. 2006) and AI-related-arthralgia (Garcia-Giralt et al. 2013).

\section{DNA extraction and polymorphism genotyping}

DNA extraction from peripheral blood was performed at the LGC genomics facilities. Polymorphism genotyping was carried out using KASPar v4.0 genotyping systems at the LGC genomics facilities (LGC, Hoddesdon, Hertfordshire, UK). To ensure genotyping quality, a random sample (5\% of the total number of samples) was also genotyped in a separate control plate. There was 100\% concordance between these results.

\section{Statistical analyses}

Hardy-Weinberg equilibrium (HWE) was calculated by $\chi^{2}$. HWE $P$ values for all the SNPs were calculated using the Tufts University website template (http://www.tufts.edu/ mcourt01/Documents/Court\%201ab\%20-\%20HW\% 20calculator.xls).

The outcome was AIBL, calculated as the cumulative LS and FN BMD percent changes at each assessment (1 and 2 years follow-up). BMD changes from baseline were evaluated using Student $t$-test for paired samples.

Multivariate linear regressions (log-additive, dominant and recessive models) were used to assess the association between the studied SNPs and AIBL at 1 and 2 years followup. Models were adjusted for age, BMI and previous tamoxifen and chemotherapy. Potential confounding for baseline $25(\mathrm{OH}) \mathrm{D}$ concentrations and type of $\mathrm{AI}$ was assessed. To minimize false discovery due to multiple testing, we performed the false discovery rate correction (FDR) (Benjamini et al. 2001), accepting all predictions with $q<0.05$ as significant.

Haplotype frequencies for the significant SNPs on CYP11A1 were estimated using expectation maximization algorithm. Association between haplotypes and AIBL was tested by haplo.glm, based on a glm regression analysis, controlling for age, BMI and previous tamoxifen and chemotherapy. We assumed an additive model, where haplotype-specific parameters represent the coefficient of AIBL. The most common haplotype was used as the reference.

All analyses were two-tailed. Statistical analyses were performed using R for Windows version 2.13.2 (packages: SNPassoc, foreign, multtest and haplo.stats).

\section{Human osteoblast culture}

Human primary osteoblasts (hOB) were obtained from trabecular bone of three post-menopausal women who

Published by Bioscientifica Ltd 


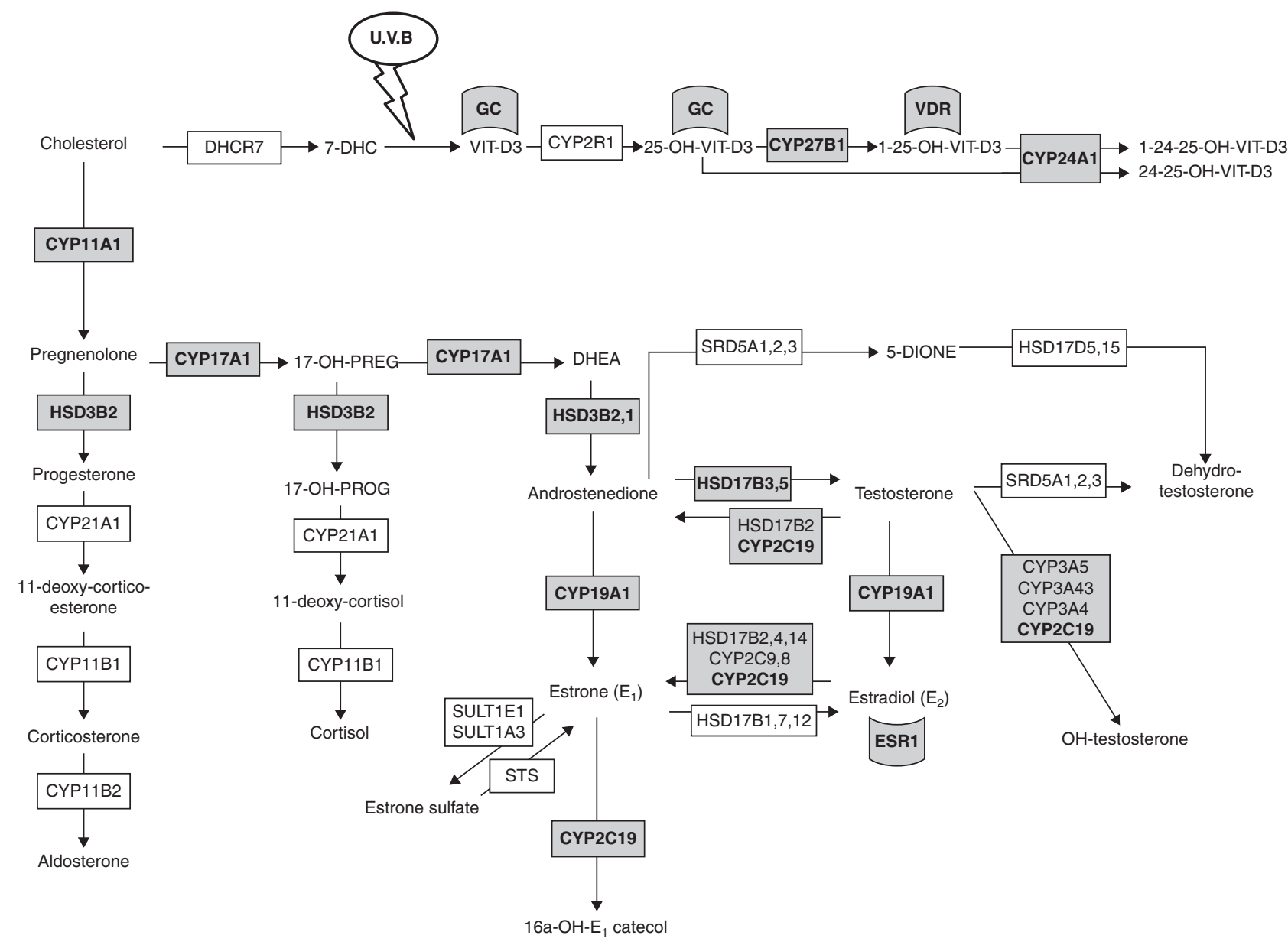

Figure 1

Schematic diagram of metabolites and enzymes of steroid and vitamin D signaling pathways. Selected genes for the association analyses are marked in grey boxes and bold font.

underwent hip replacement due to osteoarthritis. Bony tissue was cut up into small pieces, washed in phosphate buffered solution (PBS, Gibco by Life Technologies) to remove non-adherent cells and placed on a $140 \mathrm{~mm}$ culture plate. Samples were incubated in DMEM (Gibco, Invitrogen), supplemented with 10\% FBS (Sigma-Aldrich), $100 \mathrm{U} / \mathrm{ml}$ penicillin/streptomycin (Sigma-Aldrich), $0.4 \%$ fungizone (Gibco by Life Technologies) and $100 \mu \mathrm{g} / \mathrm{ml}$ ascorbic acid (Sigma). This allowed osteoblastic cells to migrate from the fragments and proliferate. All experiments were performed at passage 0 .

\section{Total RNA extraction}

RNA from hOB cultures $(n=2)$ was extracted using High Pure RNA Isolation kit (Roche Diagnostics) according to manufacturer instructions.
Total bone RNA was obtained from FN trabecular bone of two post-menopausal women who underwent hip replacement due to osteoarthritis. Bone samples were cut up into small fragments, washed in PBS and incubated 10 min in Tri-Reagent solution (Sigma-Aldrich). After a vigorous vortex, chloroform (Merk, Darmstadt, Germany) was added to the sample, followed by centrifugation for $15 \mathrm{~min}$ at $12000 \mathrm{~g}$. The upper water phase was collected and extraction continued according to manufacturer instructions (TRI Reagent Protocol, Sigma-Aldrich). Concentration of the purified RNA was analyzed on a spectrophotometer (Nanodrop, Thermo Fisher Scientific, Inc., Wilmington, DE, USA). RNA preparations were considered acceptable for RT-PCR when their A260 (nm)/A280 (nm) ratios were $>1.8$. The integrity of the RNA preparations was verified by $1 \%$ (w/v) agarose (Agarose D-1 Low EEO, Conda, Pronadisa, Madrid, Spain) bleach gel (1\% (v/v) commercial chlorine bleach) electrophoresis (Aranda et al. 2012).

Published by Bioscientifica Ltd. 


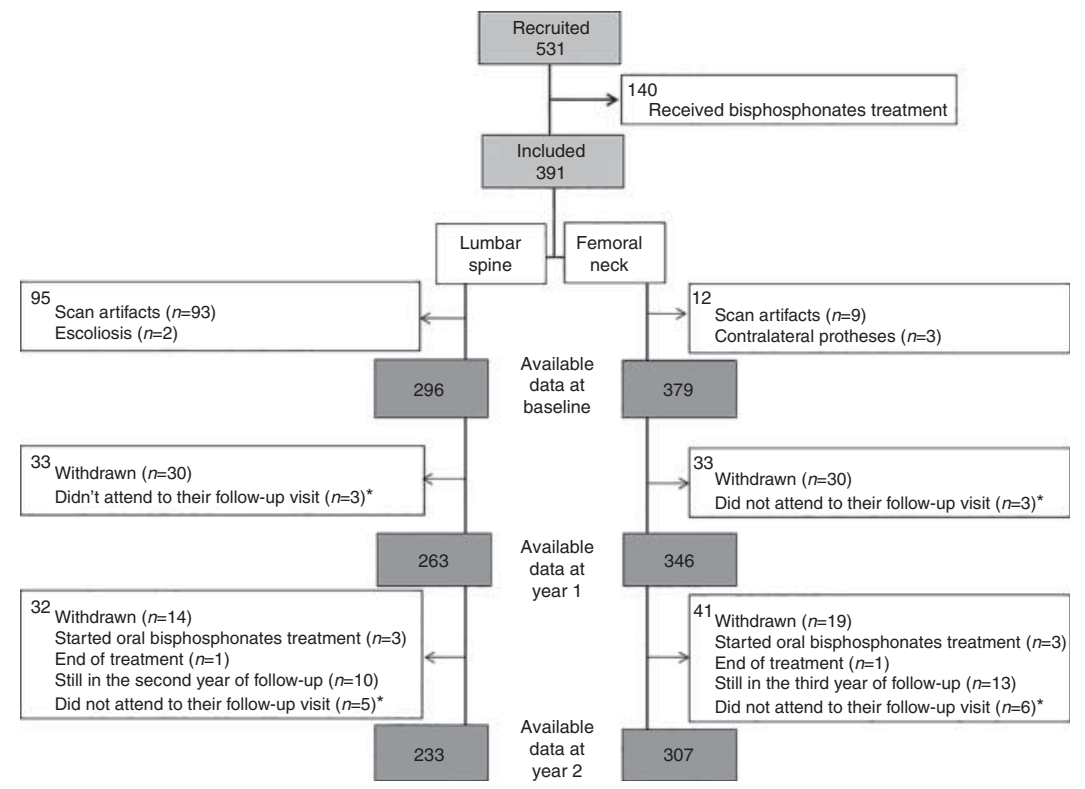

Figure 2

Flow-chart showing the number of patients at baseline and at each follow-up visit until 2 years of Al-treatment. (*) Patients not withdrawn from the study.

\section{CYP11A1 and CYP17A1 mRNA expression analysis}

RT-PCR was performed using the High Capacity cDNA RT Kit (Applied Biosystems) according to manufacturer protocol. The reaction volume was set to $20 \mu \mathrm{l}$ containing $1.1 \mu \mathrm{g}$ of total RNA.

CYP11A1 primer pairs for PCR were: $\mathrm{F} 5^{\prime}$-CCGTGACCCTGCAGAGATAT-3' and R 5'-TGGTCATCTCTAGCTC AGCG $-3^{\prime}$, encompassing exons 7 and 8 of isoform 1 (NM_000781.2) and resulting in an amplification product of 249 base pairs.
CYP17A1 primer pairs for PCR were: F 5'-AAGGGCAAGGACTTCTCTGGGCGG-3' and R 5'-AGGGTTTTGTTGGGGAAAAT-3', encompassing exons 2 and 3 of isoform 1 (NM_000102.3) and resulting in an amplification product of 422 base pairs.

\section{Western blotting}

Cultured hOBs $(n=5)$ were washed with PBS and then incubated with loading buffer $(62.5 \mathrm{mM}$ Tris- $\mathrm{HCl}(\mathrm{pH} 6.8)$, $10 \% \quad(\mathrm{v} / \mathrm{v})$ glycerol, $2 \% \quad(\mathrm{w} / \mathrm{v})$ SDS, $0.004 \% \quad(\mathrm{w} / \mathrm{v})$

Table 1 Baseline patient characteristics

\begin{tabular}{l} 
Patient characteristic ( $N=\mathbf{3 9 1}$ ) \\
\hline Mean age (years) (s.D.) \\
Mean BMI (s.D.) \\
Mean age of menopause onset (years) (s.D.) \\
Median age of menarche (IQ) \\
Median breastfeeding (In months) (IQ) \\
Median number of children (IQ) \\
Prior tamoxifen therapy $n(\%)$ \\
Prior chemotherapy $n(\%)$ \\
Aromatase inhibitor $n(\%)$ \\
Letrozole \\
Exemestane \\
Anastrozole \\
Bone mineral density \\
Lumbar spine \\
Femoral neck
\end{tabular}

\begin{tabular}{ccc}
$\begin{array}{c}\text { Mean } \pm \text { s.D. } \\
\text { Median (IQ) }\end{array}$ & $\boldsymbol{n}(\%)$ \\
\hline $61.3 \pm 8.5$ & \\
$29.5 \pm 5.4$ & \\
$49.3 \pm 4.5$ & \\
$12(3)$ & \\
$3(11)$ & \\
$2(2)$ & $235(40.7 \%)$ \\
& $262(67.0 \%)$ \\
& $124(31.7 \%)$ \\
& $5(1.3 \%)$ \\
$0.961 \pm 0.109$ & \\
$0.747 \pm 0.085$ & \\
\hline
\end{tabular}

IQ, interquartile range; S.D., standard deviation. 


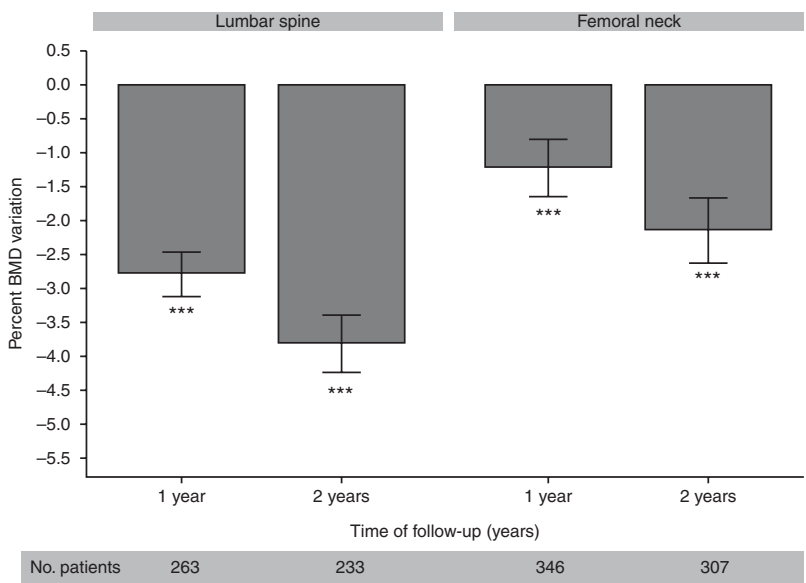

Figure 3

Cumulative individual percent change (mean $(95 \% \mathrm{Cl})$ ) in bone mineral density of the lumbar spine and femoral neck up to 2 years on Al-therapy. $* * *$ (In paired $t$-test: $P<0.001)$. BMD, bone mineral density.

bromophenol blue and 30\% (v/v) 2-mercaptoethanol) containing complete protease inhibitors solution (Protease Inhibitor Cocktail Tablets, Roche). Cell lysates were boiled 5 min at $95^{\circ} \mathrm{C}$, fractionated by SDS-PAGE and transferred to a nitrocellulose membrane using a Mini-Protean cell (Bio-Rad Laboratories S.A.) according to manufacturer instructions.

The human cholesterol side-chain cleavage enzyme (encoded by CYP11A1 gene) and the steroid 17-alphamonooxygenase (encoded by CYP17A1 gene) were detected using the anti-CYP11A1 rabbit polyclonal antibody (ab175408, Abcam, Cambridge, UK) in a 1:500 dilution in blocking solution and the anti-CYP17A1 rabbit polyclonal antibody (ab80206, Abcam) in a 1:50 dilution, respectively. The anti-actin mouse monoclonal antibody (ab3280, Abcam) was used as loading control in a 1:500 dilution. Horseradish peroxidase-conjugated anti-rabbit antibody (Thermo scientific, Rockford, IL, USA), at 1:2500 dilution, was used for detection of the cholesterol sidechain cleavage enzyme and steroid 17-alpha-monooxygenase. Horseradish peroxidase-conjugated polyclonal Goat Anti-mouse (Dako Denmark, Glostrup, Denmark) was used for actin detection at 1:2500 dilution.

\section{Results}

\section{Baseline patient characteristics and AIBL assessment}

A total of 531 women were recruited from February 2006 to February 2013 in the B-ABLE cohort. Of these, 391 were not treated with BP and were selected for the genotyping study. Patients with spine scan artifacts and/or scoliosis $(n=95)$ and those with hip scan artifacts or bilateral prostheses ( $n=12$ ) were excluded from the study (Fig. 2). Three patients developed osteoporosis during the second year of AI treatment. They were immediately offered oral $\mathrm{BP}$ treatment and, from then on, their recorded data were also omitted from analysis.

Baseline patients eligible for the AIBL study totaled 296 for LS and 379 for FN. Of these, 263 patients with LS measurement (88.8\%) and 346 (91.3\%) with FN measurement completed 1 year of AI-treatment. At 2 years, 233 patients (78.7\%) with LS and 307 (81\%) with FN measurements had available data. Baseline clinical characteristics of the study participants are shown in Table 1.

The intra-individual cumulative percent change in BMD at LS was $-2.79 \%$ (95\% CI: -3.11 to $-2.46 ; P<0.001$ ) at 1 year and $-3.82 \%$ (95\% CI: -4.24 to $-3.40 ; P<0.001)$ at 2 years and at FN was $-1.22 \%$ (95\% CI: -1.64 to -0.80 ; $P<0.001)$ at 1 year and -2.14 (95\% CI: -2.62 to -1.67 ; $P<0.001$ ) at 2 years (Fig. 3).

Analysis of patient distribution by categories of BMD change revealed that 80.3 and $61.6 \%$ of patients experienced BMD loss both at LS and FN, respectively, after 2 years on AI therapy, with more than half of them showing losses $>3 \%$. In contrast, 19.8 and $38.4 \%$ of patients

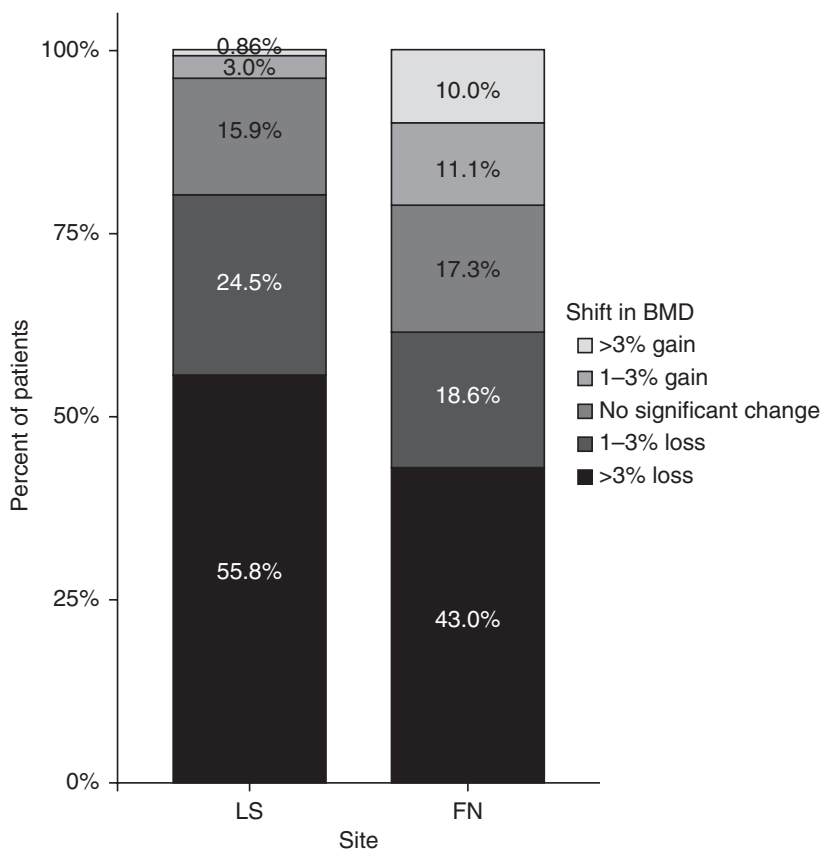

Figure 4

Percentages of patient distribution in bone mineral density shift category for lumbar spine and femoral neck after 2 years on Al-treatment. Three patients assigned to BP-non treated group at baseline reached T-scores $<-2.0$ and were immediately started on active treatment. $B M D$, bone mineral density; LS, lumbar spine; FN, femoral neck.

Published by Bioscientifica Ltd 
Table 2 Characteristics of the SNPs selected for genotyping

\begin{tabular}{|c|c|c|c|c|c|c|}
\hline Hypotheses & Locus & SNP ID & Alleles (R/A) & MAF (*) & HWE P value* & $\begin{array}{c}\text { Genotyping } \\
\text { efficiency (\%) }\end{array}$ \\
\hline \multirow[t]{17}{*}{ Steroid pathway } & \multirow[t]{2}{*}{ CYP19A1 } & rs1062033 & $C / G$ & $0.45(\mathrm{G})$ & 0.538 & 98.5 \\
\hline & & rs4775936 & $\mathrm{C} / \mathrm{T}$ & $0.47(\mathrm{~T})$ & 0.837 & 96.9 \\
\hline & \multirow[t]{2}{*}{ CYP17A1 } & rs4919687 & $\mathrm{G} / \mathrm{A}$ & $0.30(\mathrm{~A})$ & 0.113 & 98.2 \\
\hline & & rs6163 & $\mathrm{C} / \mathrm{A}$ & $0.43(\mathrm{~A})$ & 0.063 & 98.9 \\
\hline & \multirow[t]{3}{*}{ CYP11A1 } & rs4077581 & $\mathrm{T} / \mathrm{C}$ & $0.36(C)$ & 0.741 & 97.9 \\
\hline & & rs900798 & $\mathrm{G} / \mathrm{T}$ & $0.39(\mathrm{~T})$ & 0.392 & 97.4 \\
\hline & & rs11632698 & $\mathrm{G} / \mathrm{A}$ & $0.47(\mathrm{~A})$ & 0.259 & 97.4 \\
\hline & \multirow[t]{2}{*}{ HSD3B2 } & rs2854964 & $\mathrm{A} / \mathrm{T}$ & $0.34(\mathrm{~T})$ & 0.910 & 99.0 \\
\hline & & rs3765948 & $\mathrm{T} / \mathrm{C}$ & $0.15(C)$ & 0.845 & 99.5 \\
\hline & \multirow[t]{3}{*}{ HSD17B3 } & rs408876 & $\mathrm{G} / \mathrm{A}$ & $0.14(\mathrm{~A})$ & 0.537 & 99.2 \\
\hline & & rs2066474 & $\mathrm{G} / \mathrm{A}$ & $0.18(\mathrm{G})$ & 0.222 & 99.0 \\
\hline & & rs2183009 & A/G & $0.35(\mathrm{~A})$ & 0.090 & 97.7 \\
\hline & \multirow[t]{3}{*}{ CYP2C19 } & rs12248560 & $\mathrm{C} / \mathrm{T}$ & $0.19(\mathrm{~T})$ & 0.631 & 99.2 \\
\hline & & rs3758581 & $\mathrm{G} / \mathrm{A}$ & $0.07(\mathrm{~A})$ & 0.000 & 98.4 \\
\hline & & rs4244285 & $\mathrm{G} / \mathrm{A}$ & $0.14(\mathrm{~A})$ & 1.000 & 97.5 \\
\hline & CYP2C9 & rs28371674 & $\mathrm{C} / \mathrm{T}$ & $0.16(\mathrm{~T})$ & 0.460 & 98.0 \\
\hline & ESR1 & rs2504063 & $\mathrm{G} / \mathrm{A}$ & $0.45(\mathrm{~A})$ & 0.182 & 98.2 \\
\hline \multirow[t]{10}{*}{ Vitamin D pathway } & \multirow[t]{2}{*}{ CYP27B1 } & rs10877012 & $\mathrm{G} / \mathrm{T}$ & $0.24(\mathrm{~T})$ & 1.000 & 99.7 \\
\hline & & rs4646536 & $\mathrm{G} / \mathrm{A}$ & $0.25(\mathrm{G})$ & 1.000 & 99.5 \\
\hline & GC & rs3755967 & $\mathrm{C} / \mathrm{T}$ & $0.31(\mathrm{~T})$ & 0.722 & 97.9 \\
\hline & \multirow[t]{3}{*}{ CYP24A1 } & rs6013897 & T/A & $0.22(\mathrm{~A})$ & 0.376 & 98.5 \\
\hline & & rs11907350 & $\mathrm{G} / \mathrm{A}$ & $0.04(\mathrm{~A})$ & 0.081 & 99.0 \\
\hline & & rs4809957 & A/G & $0.24(G)$ & 0.160 & 97.7 \\
\hline & \multirow[t]{4}{*}{ VDR } & rs2544037 & $\mathrm{A} / \mathrm{G}$ & $0.39(\mathrm{G})$ & 0.286 & 98.7 \\
\hline & & rs11568820 & $\mathrm{C} / \mathrm{T}$ & $0.23(\mathrm{~T})$ & 0.670 & 97.4 \\
\hline & & rs1544410 & $\mathrm{G} / \mathrm{A}$ & $0.35(\mathrm{~A})$ & 0.434 & 98.2 \\
\hline & & rs17879735 & C/A & $0.47(\mathrm{~A})$ & 0.919 & 98.2 \\
\hline
\end{tabular}

R, reference allele; A, alternative allele; ma, minor allele frequency; HWE, Hardy-Weinberg equilibrium. *(In B-ABLE cohort). In bold, HWE $P$ values deviated from HWE.

showed no BMD changes or increases, at LS and FN, respectively (Fig. 4).

\section{Genetic association with AIBL}

MAF and HWE $P$ value for each genotyped SNP in the B-ABLE cohort are reported in Table 2. Three SNPs (rs4077581, rs11632698 and rs900798) in the CYP11A1 gene were associated with BMD variation in $\mathrm{FN}$ at 2 years of AI treatment. $P$ values and $\beta$ coefficients $(95 \% \mathrm{CI})$ are shown in Table 3.

The haplotype frequencies predicted by the expectation-maximization algorithm for these SNPs are shown in Table 4. The haplotype TGG (reference haplotype) was the most frequent haplotype in our cohort. Inheritance of one copy of the haplotype CAT was associated

Table 3 Associated SNPs with FN BMD variation in linear-regression analysis

\begin{tabular}{|c|c|c|c|c|c|c|}
\hline Locus & SNP & Genotype groups & $n$ & $\beta$ coefficient $^{\mathrm{a}}(95 \% \mathrm{CI})$ & $P$ value & FDR adj. $P$ value \\
\hline \multirow[t]{9}{*}{ CYP11A1 } & rs4077581 & $\mathrm{T} / \mathrm{T}$ & 122 & $0.98(0.30-1.66)$ & $0.005^{b}$ & 0.045 \\
\hline & & $\mathrm{T} / \mathrm{C}$ & 138 & & & \\
\hline & & $\mathrm{C} / \mathrm{C}$ & 43 & & & \\
\hline & rs900798 & G/G & 113 & $1.06(0.39-1.72)$ & $0.002^{b}$ & 0.045 \\
\hline & & $\mathrm{T} / \mathrm{G}$ & 140 & & & \\
\hline & & $\mathrm{T} / \mathrm{T}$ & 50 & & & \\
\hline & rs11632698 & G/G & 85 & $0.94(0.30-1.58)$ & $0.004^{b}$ & 0.045 \\
\hline & & $\mathrm{G} / \mathrm{A}$ & 142 & & & \\
\hline & & $\mathrm{A} / \mathrm{A}$ & 75 & & & \\
\hline
\end{tabular}

${ }^{a}$ Adjusted by: age, BMI, previous chemotherapy treatment and previous tamoxifen treatment.

${ }^{\mathrm{b}}$ Additive model.

http://jme.endocrinology-journals.org DOI: 10.1530/JME-15-0079
(C) 2015 Society for Endocrinology Printed in Great Britain 
Table 4 Association between haplotypes and FN BMD loss at year 2 for three SNPs in CYP11A1

\begin{tabular}{|c|c|c|c|}
\hline \multirow[b]{2}{*}{ Haplotypes $^{a}$} & \multicolumn{3}{|c|}{ Coefficient $^{\mathrm{b}}(95 \% \mathrm{CI})$} \\
\hline & Frequence & Each copy of haplotype & $P$ value \\
\hline $\mathrm{TGG}^{\mathrm{c}}$ & 0.517 & Ref & Ref \\
\hline CAT & 0.368 & $0.99(0.29-1.69)$ & 0.006 \\
\hline TAG & 0.087 & $0.26(-0.96$ to 1.47$)$ & 0.676 \\
\hline TAT & 0.026 & $1.03(-0.96$ to 1.47$)$ & 0.342 \\
\hline
\end{tabular}

${ }^{a}$ Haplotypes were constructed for: rs4077581, rs11632698 and rs900798.

${ }^{\mathrm{b}}$ Adjusted by: age, BMI, previous chemotherapy treatment and previous tamoxifen treatment.

'Major haplotype (reference haplotype)

with $0.99 \%$ less BMD loss at 2 years of AI treatment, compared to the reference haplotype $(P=0.006)$. Therefore, at 2 years of follow-up, patients carrying 2 copies of the haplotype CAT experienced half of the BMD loss $(-2.05 \%)$ observed in patients carrying two copies of the referent haplotype $(-4.03 \%)$.

\section{CYP11A1 and CYP17A1 expression in human FN bone and primary osteoblasts.}

CYP11A1 (Fig. 5A) and CYP17A1 (Fig. 6A) mRNA expression was detected both in fresh bone tissue and in cultured osteoblasts obtained from the bone samples. Although CYP17A1 was not associated with AIBL, we considered to assess its expression in bone since it is the only enzyme in the estrogen synthesis pathway not previously described in this tissue.

At the protein level, both common isoforms of cholesterol side-chain cleavage enzyme according to the UniProt database (P05108-CP11A_HUMAN) were detected in cultured hOB: One $60 \mathrm{kDa}$ band corresponding to isoform 1: NP_000772.2 and one $42 \mathrm{kDa}$ band corresponding to truncated isoform 2: NP_001093243.1 (Fig. 5B). The steroid 17-alpha-monooxygenase protein was also detected in hOB cells (Fig. 6B).

\section{Discussion}

SNPs in candidate genes that participate in estrogen and vitamin $\mathrm{D}$ hormone-response pathways were genotyped to analyze their association with AIBL. Three tag-SNPs located in the CYP11A1 gene region were significantly associated with AIBL at 2 years of treatment. The nominal association of these SNPs at 1 year of follow-up supports this association. Next, we demonstrated the CYP11A1 RNA expression in fresh FN bone tissue and primary osteoblasts obtained from this tissue. At the protein level, both common isoforms of cholesterol side-chain cleavage enzyme were detected in hOB, suggesting a potential role of this cytochrome $\mathrm{P} 450$ enzyme in bone metabolism.

The CYP11A1 gene encodes the cholesterol side-chain cleavage enzyme (alternatively, P450scc), which catalyzes

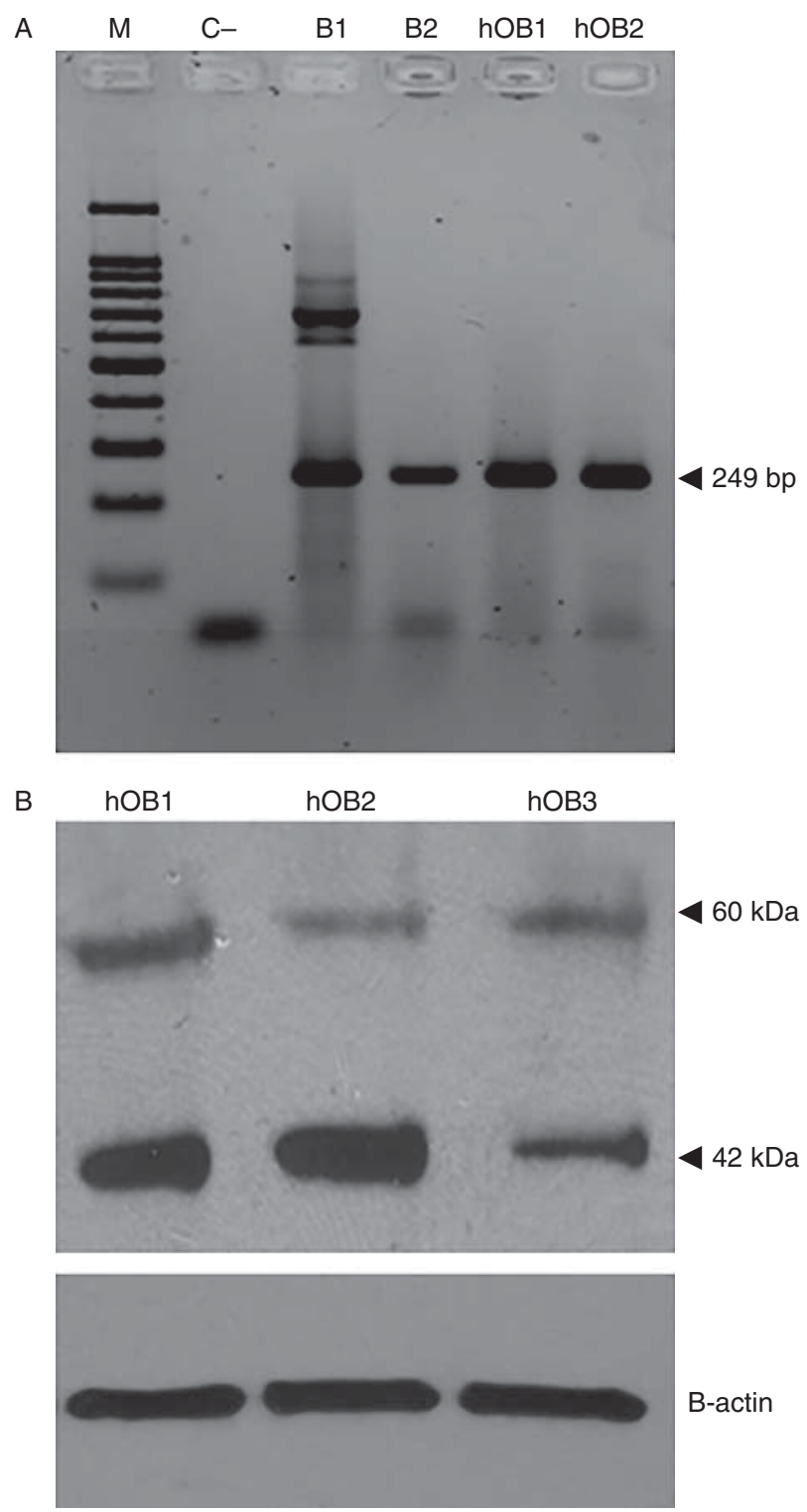

Figure 5

(A) RT-PCR product of CYP11A1 gene expression in primary osteoblasts and total bone tissue from femoral neck. M:1000pb ladder nucleic acid marker; $\mathrm{C}-$ : negative control; B1 and B2: femoral neck bone tissue. The upper bands of lane B1 correspond to genomic amplification; hOB1 and 2: femoral neck primary osteoblasts. (B) CYP11A1 protein and B-actin identified by western blot. hOB1, 2 and 3: protein expression in femoral neck primary osteoblasts. Two different isoforms were detected: the full length $60-\mathrm{kDa}$ (521 aa) protein and a shorter isoform known as isoform $\mathrm{b}$ of $42-\mathrm{kDa}$ (363 aa), missing aa from 1 to 158 from the canonical sequence. It is regulated by alternative splicing and utilization of an internal translational start codon.

Published by Bioscientifica Ltd 


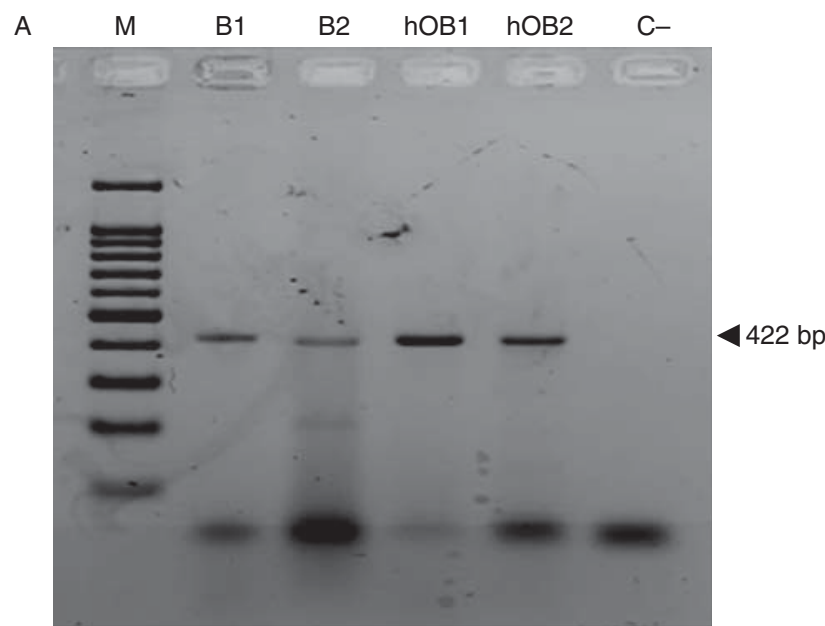

B
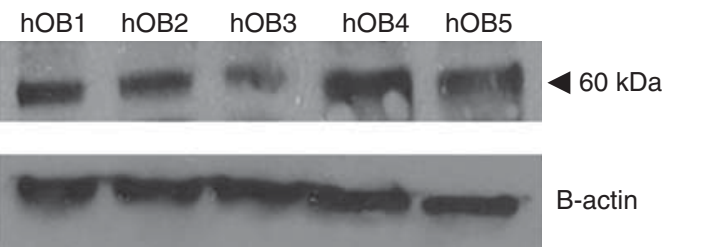

\section{Figure 6}

(A) RT-PCR product of CYP17A1 gene expression in primary osteoblasts and total bone tissue from femoral neck. M:1000pb ladder nucleic acid marker; B1 and B2: femoral neck bone tissue; hOB1 and 2: primary osteoblasts from femoral neck trabecular bone; $\mathrm{C}-$ : negative control. (B) CYP17A1 protein and $\mathrm{B}$-actin identified by western blot. hOB1-5: protein expression in femoral neck primary osteoblasts.

the first, and rate-limiting step in steroidogenesis, converting cholesterol to pregnenolone by side-change cleavage (Fig. 1). In addition to converting cholesterol, P450scc can also hydroxylate vitamin $\mathrm{D}_{2}$, vitamin $\mathrm{D}_{3}$ and their precursors (Slominski et al. 2006, Tuckey et al. 2008, Nguyen et al. 2009), suggesting a broad spectrum of roles in cell metabolism. This enzyme is a mitochondrial membrane-bound protein mainly expressed in the adrenal cortex, ovary, testis and placenta (Payne \& Hales 2004). Moreover, Teplyuk et al. (2009) detected the expression of one N-terminally truncated CYP11A1 isoform in mouse and human osteoblastic cell lines, regulated by RUNX2. This $32-\mathrm{kDa}$ isoform was localized in cytoplasm and nucleus but not in the mitochondria; its function remains unknown.

In our study, SNPs in CYP11A1 gene: rs4077581 (located in the promoter region), rs11632698 (in the intron 2) and rs900798 (in the $3^{\prime}$ region) were associated with BMD loss at FN. A statistical trend toward significance was also found between BMD loss at LS and SNPs rs4077581 $(P=0.042)$ and $\operatorname{rs900798}(P=0.029)$, after 2 years of AI treatment. All the scans in the study were evaluated for artifacts and/or structure changes that might have spuriously elevated BMD. This procedure had implications mainly for LS results, since spinal degenerative changes can notably increase BMD measurements. If all vertebrae were affected, the spine was reported as 'invalid,' with BMD results immediately omitted from the study. This substantially reduced the number of patients available to test this hypothesis, which could explain the difference in the statistical significance obtained for LS and FN in these SNPs.

Genetic variants may alter CYP11A1 expression or activity, determining sex steroid hormone levels responsible for quantitative phenotypes that include hormone-related disorders. Supporting these hypotheses, other polymorphic variants in this gene have been previously associated with breast and endometrial (Terry et al. 2010) cancer susceptibility (Zheng et al. 2004, Sun et al. 2012) and polycystic ovary syndrome (Gao et al. 2010).

The capacity of bone to synthesize estrogens has been known for a long time. However, these findings were always confined to enzymes acting downstream of DHEA. Thus, for example, the expression of HSD3B, aromatase, 17b-HSD and steroid sulfatase enzymes in bone has been detected (Saito \& Yanaihara 1998, Janssen et al. 1999). Interestingly, we found that CYP11A1 and CYP17A1 (the gene encoding for the enzyme steroid 17-alpha-monooxygenase, which acts upon pregnenolone and then upon 17-hydroxypregnenolone to form DHEA) are also expressed in human bone tissue and osteoblasts. Taken together, all enzymes in the steroid synthesis pathway have been identified in osteoblastic cells, suggesting a potential capacity of bone to synthesize its own sex hormones from cholesterol, independently of serum steroids secreted by adrenal gland, gonad and placenta. This process takes on special importance after menopause, when plasma estrogen levels are strongly deprived and estrogen synthesis is relegated to extragonadal sites. Accordingly, localized estrogen synthesis in osteoblasts is more active in postmenopausal women (Janssen et al. 1999). Therefore, the activity of CYP11A1, CYP17A1 and other enzymes involved in estrogen synthesis within bone tissue could have a central role in the local steroid sex hormone levels responsible for AIBL.

Genetic variants in other genes in the sex-steroid synthesis pathways (HSD17B3, CYP2C9, CYP19A1 and CYP2C19) have shown a trend of association with AIBL in our cohort study, but statistical significance after multiple testing correction was not achieved (data not shown). Napoli et al. (2013) found the SNP rs700518 (G/A at

Published by Bioscientifica Ltd 
Val(80)) in the CYP19A1 gene associated with AIBL at the LS and the total hip at 12 months. Hence, we cannot rule out that genetic variants in these genes, which act downstream of CYP11A1, could also intervene in the bone metabolism regulation. The same occurred with crucial genes in the vitamin D-synthesis pathway (CYP24A1 and VDR), suggesting once more the importance of this hormone in the attenuation of AI side effects such as arthralgia and bone loss (Prieto-Alhambra et al. 2012, Garcia-Giralt et al. 2013).

One limitation of the present study is the number of patients finally included in this specific analysis of our cohort, which does not permit detection of subtle allelic effects. Hence, our results need further replication in larger studies. However, to our knowledge this is the largest cohort available to date for AIBL genetic studies.

In conclusion, the CYP11A1 gene was associated with bone loss secondary to AI therapy. Moreover, CYP11A1 and CYP17A1 expression have been detected in total human bone and in osteoblasts. This is the first time that both common isoforms of CYP11A1 protein have been detected in primary osteoblasts, revealing a potential function of this enzyme in bone metabolism regulation and especially in the action of AI in the bone tissue. The presence in bone of all enzymes in the steroid-synthesis pathway opens up the possibility that this tissue can synthesize androgens and estrogens independently of serum steroid precursors.

\section{Declaration of interest}

The Authors declare that there is no conflict of interest that could be perceived as prejudicing the impartiality of the research reported.

\section{Funding}

This work was supported by the Red Temática de Investigación Cooperativa en Envejecimiento y Fragilidad (RETICEF, RD12/0043/0022), and the Grant FIS PI10/01464 and PI13/00444 (Carlos III Health Institute, Science and Innovation Ministry); Grants from the Generalitat de Catalunya (DIUE 2014 SGR 775) and FEDER funds have supported this study.

\section{Acknowledgements}

The authors thank Elaine M Lilly, for English correction, helpful advice and critical reading of the manuscript.

\section{References}

Aranda PS, LaJoie DM \& Jorcyk CL 2012 Bleach gel: a simple agarose gel for analyzing RNA quality. Electrophoresis 33 366-369. (doi:10.1002/elps. 201100335)
Benjamini Y, Drai D, Elmer G, Kafkafi N \& Golani I 2001 Controlling the false discovery rate in behavior genetics research. Behavioural Brain Research 125 279-284. (doi:10.1016/S0166-4328(01)00297-2)

Blake G, Adams JE \& Bishop N 2013 DXA in adults and children. In Primer on the Metabolic Bone Diseases and Disorders of Mineral Metabolism, 8th Edn, pp251-260. Oxford, UK: Wiley-Blackwell.

Bouvard B, Soulie P, Hoppe E, Georgin-Mege M, Royer M, MesgouezNebout N, Lassalle C, Cellier P, Jadaud E, Abadie-Lacourtoisie S et al. 2014 Fracture incidence after 3 years of aromatase inhibitor therapy. Annals of Oncology 25 843-847. (doi:10.1093/annonc/mdu008)

Brufsky AM, Bosserman LD, Caradonna RR, Haley BB, Jones CM, Moore HC, Jin L, Warsi GM, Ericson SG \& Perez EA 2009 Zoledronic acid effectively prevents aromatase inhibitor-associated bone loss in postmenopausal women with early breast cancer receiving adjuvant letrozole: Z-FAST study 36-month follow-up results. Clinical Breast Cancer 9 77-85. (doi:10.3816/CBC.2009.n.015)

Cranney A, Horsley T, O’Donnell S, Weiler H, Puil L, Ooi D, Atkinson S, Ward L, Moher D, Hanley D et al. 2007 Effectiveness and safety of vitamin D in relation to bone health. Evidence Report/Technology Assessment 158 1-235.

Eastell R, Hannon RA, Cuzick J, Dowsett M, Clack G \& Adams JE 2006 Effect of an aromatase inhibitor on bmd and bone turnover markers: 2-year results of the Anastrozole, Tamoxifen, Alone or in Combination (ATAC) trial (18233230). Journal of Bone and Mineral Research 21 1215-1223. (doi:10.1359/jbmr.060508)

Eastell R, Adams JE, Coleman RE, Howell A, Hannon RA, Cuzick J, Mackey JR, Beckmann MW \& Clack G 2008 Effect of anastrozole on bone mineral density: 5-year results from the anastrozole, tamoxifen, alone or in combination trial 18233230. Journal of Clinical Oncology 26 1051-1057. (doi:10.1200/JCO.2007.11.0726)

Enjuanes A, Garcia-Giralt N, Supervia A, Nogues X, Ruiz-Gaspa S, Bustamante M, Mellibovsky L, Grinberg D, Balcells S \& Diez-Perez A 2006 A new SNP in a negative regulatory region of the CYP19A1 gene is associated with lumbar spine BMD in postmenopausal women. Bone 38 738-743. (doi:10.1016/j.bone.2005.10.010)

Eriksen EF \& Glerup H 2002 Vitamin D deficiency and aging: implications for general health and osteoporosis. Biogerontology 3 73-77. (doi:10.1023/A:1015263514765)

Felson DT, Zhang Y, Hannan MT, Kiel DP, Wilson PW \& Anderson JJ 1993 The effect of postmenopausal estrogen therapy on bone density in elderly women. New England Journal of Medicine 329 1141-1146. (doi:10.1056/NEJM199310143291601)

Gao GH, Cao YX, Yi L, Wei ZL, Xu YP \& Yang C 2010 Polymorphism of CYP11A1 gene in Chinese patients with polycystic ovarian syndrome. Zhonghua Fu Chan Ke Za Zhi 45 191-196.

Garcia-Giralt N, Rodriguez-Sanz M, Prieto-Alhambra D, Servitja S, TorresDel Pliego E, Balcells S, Albanell J, Grinberg D, Diez-Perez A, Tusquets I et al. 2013 Genetic determinants of aromatase inhibitor-related arthralgia: the B-ABLE cohort study. Breast Cancer Research and Treatment 140 385-395. (doi:10.1007/s10549-013-2638-3)

Henry NL, Giles JT, Ang D, Mohan M, Dadabhoy D, Robarge J, Hayden J, Lemler S, Shahverdi K, Powers P et al. 2008 Prospective characterization of musculoskeletal symptoms in early stage breast cancer patients treated with aromatase inhibitors. Breast Cancer Research and Treatment 111 365-372. (doi:10.1007/s10549-007-9774-6)

Janssen JM, Bland R, Hewison M, Coughtrie MW, Sharp S, Arts J, Pols HA \& van Leeuwen JP 1999 Estradiol formation by human osteoblasts via multiple pathways: relation with osteoblast function. Journal of Cellular Biochemistry 75 528-537. (doi:10.1002/(SICI)10974644(19991201)75:3<528::AID-JCB16>3.0.CO;2-3)

Kobayashi S, Inoue S, Hosoi T, Ouchi Y, Shiraki M \& Orimo H 1996 Association of bone mineral density with polymorphism of the estrogen receptor gene. Journal of Bone and Mineral Research 11 306-311. (doi:10.1002/jbmr.5650110304)

Langdahl BL, Gravholt CH, Brixen K \& Eriksen EF 2000 Polymorphisms in the vitamin $\mathrm{D}$ receptor gene and bone mass, bone turnover and 
osteoporotic fractures. European Journal of Clinical Investigation $\mathbf{3 0}$ 608-617. (doi:10.1046/j.1365-2362.2000.00686.x)

Laroche F, Coste J, Medkour T, Cottu PH, Pierga JY, Lotz JP, Beerblock K, Tournigand C, Decleves X, de Cremoux P et al. 2014 Classification of and risk factors for estrogen deprivation pain syndromes related to aromatase inhibitor treatments in women with breast cancer: a prospective multicenter cohort study. Journal of Pain 15 293-303. (doi:10.1016/j.jpain.2013.11.004)

Muir M, Romalo G, Wolf L, Elger W \& Schweikert HU 2004 Estrone sulfate is a major source of local estrogen formation in human bone. Journal of Clinical Endocrinology and Metabolism 89 4685-4692. (doi:10.1210/jc. 2004-0049)

Napoli N, Rastelli A, Ma C, Yarramaneni J, Vattikutti S, Moskowitz G, Giri T, Mueller C, Kulkarny V, Qualls C et al. 2013 Genetic polymorphism at Val80 (rs700518) of the CYP19A1 gene is associated with aromatase inhibitor associated bone loss in women with $\mathrm{ER}+$ breast cancer. Bone 55 309-314. (doi:10.1016/j.bone.2013.04.021)

Nguyen MN, Slominski A, Li W, Ng YR \& Tuckey RC 2009 Metabolism of vitamin $\mathrm{d} 2$ to $17,20,24$-trihydroxyvitamin $\mathrm{d} 2$ by cytochrome p450scc (CYP11A1). Drug Metabolism and Disposition 37 761-767. (doi:10.1124/ dmd.108.025619)

Nogues X, Servitja S, Pena MJ, Prieto-Alhambra D, Nadal R, Mellibovsky L, Albanell J, Diez-Perez A \& Tusquets I 2010 Vitamin D deficiency and bone mineral density in postmenopausal women receiving aromatase inhibitors for early breast cancer. Maturitas 66 291-297. (doi:10.1016/ j.maturitas.2010.03.012)

Payne AH \& Hales DB 2004 Overview of steroidogenic enzymes in the pathway from cholesterol to active steroid hormones. Endocrine Reviews 25 947-970. (doi:10.1210/er.2003-0030)

Prieto-Alhambra D, Javaid MK, Servitja S, Arden NK, Martinez-Garcia M, Diez-Perez A, Albanell J, Tusquets I \& Nogues X 2011 Vitamin D threshold to prevent aromatase inhibitor-induced arthralgia: a prospective cohort study. Breast Cancer Research and Treatment 125 869-878. (doi:10.1007/s10549-010-1075-9)

Prieto-Alhambra D, Servitja S, Javaid MK, Garrigos L, Arden NK, Cooper C, Albanell J, Tusquets I, Diez-Perez A \& Nogues X 2012 Vitamin D threshold to prevent aromatase inhibitor-related bone loss: the B-ABLE prospective cohort study. Breast Cancer Research and Treatment 133 1159-1167. (doi:10.1007/s10549-012-2013-9)

Reed MJ, Purohit A, Woo LW, Newman SP \& Potter BV 2005 Steroid sulfatase: molecular biology, regulation, and inhibition. Endocrine Reviews 26 171-202. (doi:10.1210/er.2004-0003)

Reid DM, Doughty J, Eastell R, Heys SD, Howell A, McCloskey EV, Powles T, Selby P \& Coleman RE 2008 Guidance for the management of breast cancer treatment-induced bone loss: a consensus position statement from a UK Expert Group. Cancer Treatment Reviews 34 (Suppl 1) S3-18. (doi:10.1016/j.ctrv.2008.03.007)
Saito H \& Yanaihara T 1998 Steroid formation in osteoblast-like cells. Journal of International Medical Research 26 1-12.

Servitja S, Nogues X, Prieto-Alhambra D, Martinez-Garcia M, Garrigos L, Pena MJ, de Ramon M, Diez-Perez A, Albanell J \& Tusquets I 2012 Bone health in a prospective cohort of postmenopausal women receiving aromatase inhibitors for early breast cancer. Breast 21 95-101. (doi:10.1016/j.breast.2011.09.001)

Slominski A, Semak I, Wortsman J, Zjawiony J, Li W, Zbytek B \& Tuckey RC 2006 An alternative pathway of vitamin D metabolism. Cytochrome P450scc (CYP11A1)-mediated conversion to 20-hydroxyvitamin D2 and 17,20-dihydroxyvitamin D2. FEBS Journal 273 2891-2901. (doi:10.1111/j.1742-4658.2006.05302.x)

Sun M, Yang X, Ye C, Xu W, Yao G, Chen J \& Li M 2012 Risk-association of CYP11A1 polymorphisms and breast cancer among Han Chinese women in Southern China. International Journal of Molecular Sciences $\mathbf{1 3}$ 4896-4905. (doi:10.3390/ijms13044896)

Teplyuk NM, Zhang Y, Lou Y, Hawse JR, Hassan MQ, Teplyuk VI, Pratap J, Galindo M, Stein JL, Stein GS et al. 2009 The osteogenic transcription factor runx2 controls genes involved in sterol/steroid metabolism, including CYP11A1 in osteoblasts. Molecular Endocrinology 23 849-861. (doi:10.1210/me.2008-0270)

Terry K, McGrath M, Lee IM, Buring J \& De Vivo I 2010 Genetic variation in CYP11A1 and StAR in relation to endometrial cancer risk. Gynecologic Oncology 117 255-259. (doi:10.1016/j.ygyno.2010.02.002)

Tuckey RC, Li W, Zjawiony JK, Zmijewski MA, Nguyen MN, Sweatman T, Miller D \& Slominski A 2008 Pathways and products for the metabolism of vitamin $\mathrm{D}_{3}$ by cytochrome P450scc. FEBS Journal 275 2585-2596. (doi:10.1111/j.1742-4658.2008.06406.x)

Wang TJ, Zhang F, Richards JB, Kestenbaum B, van Meurs JB, Berry D, Kiel DP, Streeten EA, Ohlsson C, Koller DL et al. 2010 Common genetic determinants of vitamin $\mathrm{D}$ insufficiency: a genome-wide association study. Lancet 376 180-188. (doi:10.1016/S0140-6736(10)60588-0)

Winer EP, Hudis C, Burstein HJ, Wolff AC, Pritchard KI, Ingle JN, Chlebowski RT, Gelber R, Edge SB, Gralow J et al. 2005 American Society of Clinical Oncology technology assessment on the use of aromatase inhibitors as adjuvant therapy for postmenopausal women with hormone receptor-positive breast cancer: status report 2004. Journal of Clinical Oncology 23 619-629. (doi:10.1200/JCO.2005.09.121)

Zarrabeitia MT, Hernandez JL, Valero C, Zarrabeitia AL, Garcia-Unzueta M, Amado JA, Gonzalez-Macias J \& Riancho JA 2004 A common polymorphism in the 5 '-untranslated region of the aromatase gene influences bone mass and fracture risk. European Journal of Endocrinology 150 699-704. (doi:10.1530/eje.0.1500699)

Zheng W, Gao YT, Shu XO, Wen W, Cai Q, Dai Q \& Smith JR 2004 Population-based case-control study of CYP11A gene polymorphism and breast cancer risk. Cancer Epidemiology, Biomarkers \& Prevention 13 709-714.

Received in final form 26 May 2015

Accepted 22 June 2015

Accepted Preprint published online 24 June 2015 http://jme.endocrinology-journals.org

DOI: 10.1530/JME-15-0079
(C) 2015 Society for Endocrinology Printed in Great Britain
Published by Bioscientifica Ltd. 